\title{
Information needs in the outsourcing lifecycle
}

\author{
Gero Weimer \\ Accenture GmbH, Munich, Germany, and \\ Stefan Seuring \\ Department of International Management, University of Kassel, \\ Witzenhausen, Germany
}

\section{The outsourcing lifecycle}

Received 2 April 2007

Revised 23 July 2007 Accepted 28 August 2007

\begin{abstract}
Purpose - The purpose of this paper is to identify information needs in the outsourcing lifecycle, and to prioritize them according to their importance for governing and controlling the external provider. Design/methodology/approach - A three-round Delphi study was conducted, where 17 and 16 outsourcing experts answered, respectively.

Findings - The evaluation ranked "service reporting" as the number one information need for governing the external provider.

Research limitations/implications - The paper aims to shed light on a so far little-considered research field and to create the basis for deeper analysis. Future research activities should examine in further detail how to effectively design "service reporting" in theory and practice.

Practical implications - This involves documentation of information needs in the outsourcing lifecycle which are the major prerequisite for making decisions to govern an outsourcing project.

Originality/value - While there is a rapidly growing body of literature on outsourcing, there is hardly any account regarding what information needs have to be fulfilled in outsourcing projects along their lifecycle. This is the major contribution of the paper.
\end{abstract}

Keywords Outsourcing, Management accounting, Information transfer, Delphi method

Paper type Research paper

\section{Introduction}

The term outsourcing originates from the Anglo-Saxon language realm and is a contraction of the words Outside Resource Using. Outsourcing describes the use of external resources to execute operational tasks (Grover et al., 1994). Since, the early 1990s, outsourcing has been discussed under diverse aspects in both academic business studies and operational practice (Kakabadse and Kakabadse, 2000). In recent years, the effects of outsourcing have even been accounted for in the popular press such as the book The World is Flat by Friedman (2006).

Having started with information technology, outsourcing has now reached the so-called "white collar" realm of the company. Following the takeover of computing centers, complete application platforms, including system operations and application support, are now outsourced with the aim of decreasing related transactions cost. Thus, this reduction in vertical integration has reached the commercial areas of companies (Click and Duening, 2005).

Business process outsourcing (BPO) involves the transfer of management and execution of one or more business processes or entire business functions to an external service provider (May, 1998). BPO represents the consistent advancement

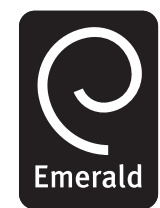

Industrial Management \& Data Systems Vol. 108 No. 1,2008 pp. 107-121 (C) Emerald Group Publishing Limited 0263-5577 
IMDS

108,1

108 of outsourcing. In addition to hard- and software, corresponding business processes are outsourced as well. The global BPO market has grown rapidly in recent years, reaching a volume of US\$ 385 billion in 2005. Moreover, market experts expect a further two-digit growth in the coming years (Ravi et al., 2006). Outsourcing concerns a multitude of companies today, and will concern even more in the future.

This paper aims to identify information needs in the outsourcing lifecycle, which are the major prerequisite for making decisions in governing an outsourcing project. We will prioritize these needs according to their importance for governing and controlling the external provider. The paper aims to shed light on a so far little-considered research field, to document first results, and to create a basis for further research activities. The remainder of the paper is organized as follows: the next sections present a brief literature review, the research methodology, and the research process conducted, where a Delphi study was carried out. Subsequently, the findings from the Delphi study are presented, the research contribution of the paper is discussed, and our conclusions will be outlined in closing.

\section{Literature review}

In the context of an outsourcing engagement, companies are facing four essential questions (Dibbern et al., 2004). Accordingly, current outsourcing research can be divided into four main areas that try to answer these questions:

(1) Why should we outsource? Research activities describe outsourcing opportunities and risks, allowing every outsourcing engagement to balance them within its own context as a key prerequisite of the outsourcing decision (Harland et al., 2005; Kakabadse and Kakabadse, 2005; Ketler and Walstrom, 1993).

(2) Which functions should be outsourced? Outsourcing research mainly uses the transaction cost theory and the resource-based theory in order to build a theoretical framework for this kind of decision (Holcomb and Hitt, 2007; Aubert et al., 2004; McIvor, 2000; Poppo and Zenger, 1998; Cheon et al., 1995).

(3) How should we conduct the outsourcing engagement? This research area deals with guidelines, mainly developed by practitioners, who recommend how to conduct an outsourcing project (de Boer et al., 2006; Power et al., 2006; Brown and Wilson, 2005; Bragg, 1998).

(4) What are the main success factors with outsourcing? Research activities try to develop the key factors leading to a successful outsourcing project or those which identify related risks (Johnson et al., 2006; Peisch, 1995; Quinn and Hilmer, 1994).

Within the fourth area, outsourcing research has identified that permanently governing and controlling the outsourcing provider is essential for a successful outsourcing engagement. Nevertheless, examinations on how to set up and operate this governance in detail are missing so far. In order to govern the outsourcing project in general and the external provider in particular, top management first of all needs sufficient information regarding what future decisions can be based on. In the field of organizational decision making, information that has to be generated by a company as a prerequisite and basis of organizational decisions is defined as 
“information need” (O'Reilly, 1983). This paper hopes to shed light on this infrequently-considered research field by identifying and prioritizing information needs in the outsourcing context.

Information is a key driver of business and business processes. It is not only required to complete any kind of operational processes, but also to meet specific decision making needs. This is reflected particularly in management accounting, where the provision of information for management decision making is a key task that has to be fulfilled (see textbooks on management accounting, e.g. Atkinson et al., 2003; Drury, 2004). Outsourcing decisions also have to be based on such information (Ezzamel et al., 2002).

But it is rather surprising that, in the outsourcing context, almost no research on the use of management accounting techniques to drive outsourcing decisions has been conducted so far (we conducted a comprehensive literature search based on major databases (EBSCO, Proquest 5000) as well as publishers (e.g. Elsevier, Emerald, Wiley), but hardly found any related papers). Looking at this intersection, some research addressed the outsourcing of the accounting function (Ezzamel et al., 2002; Smith et al., 2005) or the treatment of outsourcing in company accounts (Juma'h and Woods, 1999). Closer to the issues discussed here comes the cost estimation of outsourcing decisions, while the example presented by Sciulli (2004) basically assesses the tendering process for public contracting. This paper raises the importance of the information needs that have to be fulfilled before an outsourcing decision can take place.

Since, information needs change during an outsourcing relationship, they will be structured along the different phases of the so-called outsourcing lifecycle for the following description of findings (Power et al., 2006):

- assessment;

- transition; and

- operations phase.

Alternative labels might be:

- initiation;

- evaluation;

- management; and

- outcome stage (de Boer et al., 2006)

or:

- identification and assessment;

- audit and approval;

- project execution; and

- performance management (Momme and Hvolby, 2002).

For reasons of simplicity, we will use the three-phase model of Power et al. (2006), where the three stages are briefly explained.

The assessment phase starts by asking potential outsourcing providers to make an offer concerning the outsourcing of a specified set of business processes and functions.

\section{The outsourcing} lifecycle

109 
IMDS 108,1

110

It includes the entire process, beginning with the analysis of the as-is situation up to the development of a to-be concept including a business case calculating potential future savings. The assessment phase ends when the outsourcing contract is signed. In the transition phase, the implementation of the agreed outsourcing solution takes place. The selected business processes and functions are gradually outsourced to the external provider. The transition phase includes all measures that help to lower costs and to increase productivity. As soon as the to-be performance and service levels are reached, the operations phase begins. Based on the to-be conditions, a continuous adjustment and improvement starts which is triggered by an increasingly better understanding of in-scope business processes and functions. The operations phase, as well as the entire outsourcing relationship, end with the expiration of the contracted running time of the outsourcing project. The outsourced business processes and functions are returned from the external provider to the company which originally outsourced them.

While both prescriptive and empirical descriptions (de Boer et al., 2006) have been presented, in terms of structuring the outsourcing process, the underlying information needs have hardly been addressed. This is where management accounting information should be provided to support both the initial decision making as well as the long-term monitoring of the outsourced business processes. As mentioned, we found no directly related literature in the outsourcing context. This justifies an exploratory research approach.

\section{Research methodology}

Our research is based on an expert survey in the form of a Delphi study. "The Delphi method has proven a popular tool for identifying and prioritizing issues for managerial decision making" (Okoli and Pawlowski, 2004). The Delphi method was initially developed in the 1950s by the RAND Corporation and has been applied in numerous ways since then (Dalkey and Helmer, 1963). Linstone and Turoff (2002) summarize substantial characteristics of the Delphi method:

Delphi may be characterized as a method for structuring a group communication process so that the process is effective in allowing a group of individuals, as a whole, to deal with a complex problem. To accomplish this "structured communication" there is provided: some feedback of individual contributions of information and knowledge; some assessment of the group judgment or view; some opportunity for individuals to revise views; and some degree of anonymity for the individual responses.

As can be seen, this characterization includes substantial advantages of the Delphi method in relation to alternative inquiry methods: a Delphi study permits a repeated request of information and allows an anonymous and controlled feedback exchange between participants, which decreases the danger of opinion leaders (Dalkey and Helmer, 1963). The Delphi method also permits an evaluation of given information within the group of experts through formalizing the request by means of a questionnaire. Thus, Delphi studies inherently secure the construct validity, as the results of the preceding rounds are sent back to the experts (Okoli and Pawlowski, 2004).

Based on the Delphi concept of Linestone and Turoff (2002), different Delphi designs have been developed. Depending on the objective of an investigation, the Delphi method distinguishes four fundamental Delphi types: a brainstorming-, a forecasting- 
and a consensus-Delphi, as well as a Delphi to determine expert opinions (Häder, 2002). The latter applies for our study.

Selecting the right experts is considered one of the most important steps in the course of conducting a Delphi study. The Delphi literature recommends a panel size of 10-18 participants (Okoli and Pawlowski, 2004). When assembling the panel of experts, the researchers try to ensure that the participants are not only characterized by high-functional expertise and specialization in the field of outsourcing, but that the group also demonstrates a certain degree of heterogeneity.

The expert panel was built with practitioners. Employees from management consulting, system integration, and the outsourcing provider Accenture were selected. Accenture appeared suitable, since the company was honored recently as the most well-known outsourcing provider based on a Lünendonk (2006) inquiry surveying the managers of 30 large companies in Germany which are responsible for purchasing external services. Consultants (in contrast to outsourcing experts in companies which outsource) can build on rich experiences from many different outsourcing projects and therefore were particularly suitable for this research project. Moreover, this approach allowed an easy access to experts and had a good chance to ensure a high-return rate (Häder, 2002). Supported by Accenture's human resource department, and based on a prior developed requirement profile, a panel of 23 outsourcing experts was identified.

The researchers were aware of the limitations of an intra-company Delphi panel, particularly regarding the frequent criticism that the group of experts is too homogeneous (Häder, 2002). Therefore, they took particular care that the experts originated from different organizational departments and different hierarchic levels of Accenture, and that they worked in different industries, in order to ensure a sufficiently heterogenous expert panel. The resulting set of different expert experiences was meant to stimulate discussions in the questioning rounds, since heterogeneous groups are more creative than homogeneous ones (Okoli and Pawlowski, 2004). The 23 outsourcing experts originated from six different organizational units, are distributed over five hierarchic levels within the Accenture organization, and work in seven different industries. In order to guarantee results, the list of experts was examined one last time by the person responsible for the outsourcing business of Accenture in German-speaking countries.

\section{Findings}

Our research process is based on an ideal type of a Delphi approach which includes the phases brainstorming, consolidation and evaluation (Schmidt, 1997). The substantial steps of this approach were presented to the participants of the study as part of the cover letter for the first round. The experts were contacted by e-mail and asked for feedback within ten days. Participants who did not answer within this timeframe were contacted again by e-mail and phone up to three times. The design and length of the questionnaires were intended to enable the experts to answer within 15-20 minutes.

In early August 2006, the first questioning round asked the participants to do a comprehensive brainstorming concerning the required information needs within the three phases of the outsourcing lifecycle. In addition, experts were encouraged, as in all survey rounds, to provide comments and explanations with their answers. Prior to survey round 1 , the corresponding questionnaire was discussed and plausibility-checked in a pre-test with one of the people responsible for the

\section{The outsourcing lifecycle}

111 
IMDS 108,1

outsourcing business of Accenture. The pre-test was designed to ensure that the questionnaire actually demands the expected information. It was answered by 17 out of 23 experts.

The information needs resulting from the expert brainstorming questioning round 1 were then analyzed through a combination of structuring and recapitulating content analysis (Neuendorf, 2002). Afterwards, the results were consolidated from roughly 90 to 49 information needs, and an appropriate questionnaire for the next questioning round was developed. In order to ensure construct validity, the consolidation and the resulting questionnaires were discussed and examined in a detailed telephone interview with one of the experts. The relatively high number of 49 information needs was particularly debated, as this is much more than the recommended number of approximately 20 evaluation items (Schmidt, 1997). Both sides finally agreed to consciously accept the increased complexity in future evaluation rounds, which results from the large number of information needs, i.e. the 49 information needs can be handled very well, and a further consolidation would erase valuable details.

In the middle of September 2006, the second round was started. Questionnaires were sent to all 17 experts who participated in round 1. The experts were now asked to evaluate the information needs on a scale from 1 to 5 regarding their importance for governing and controlling the outsourcing provider. Moreover, an additional question asked the experts to mention their top five information needs and to rank them from 1 to 5 . The questioning round was answered by 16 participants, with 16 experts conducting the evaluation by scale, but only 13 answering the additional question.

The third questioning round took place in the middle of October 2006. The 16 experts who answered round 2 received the results of the statistical evaluation. In addition, the third questionnaire compared the statistical group opinion with the respective individual evaluation of the experts from the preceding round, so that everyone could compare their own evaluation directly with the statistical group opinion. The experts were asked to re-evaluate their feedback given in round 2 and to adapt it if necessary. Round 3 was answered by all 16 participants.

\section{Results}

Round 1: information needs in the outsourcing lifecycle

The initial expert brainstorming delivered the following results (information needs) within the three phases of the outsourcing lifecycle.

The starting point of all information needs in the assessment phase was the overall strategy of the company that plans to outsource business processes or an entire business function. The as-is situation and the overall objective of the company is needed which ultimately drives the objective of the outsourcing project. If these parameters are clarified, the exact scope of the outsourcing project has to be discussed. The scope is the major driver for all further information needs and therefore should be specified precisely and very carefully. Detailed steps on how to define the scope of an outsourcing project, from the selection of the outsourcing-type (step 1) to the decision whether employees will be transferred (step 6), are shown in Figure 1.

After having defined the scope of the outsourcing project, the as-is situation must be described. The so-called baseline covers organizational aspects (e.g. number and geographical distribution of sites, or number, age structure, and qualifications of employees for each function), the supporting processes and IT landscape 


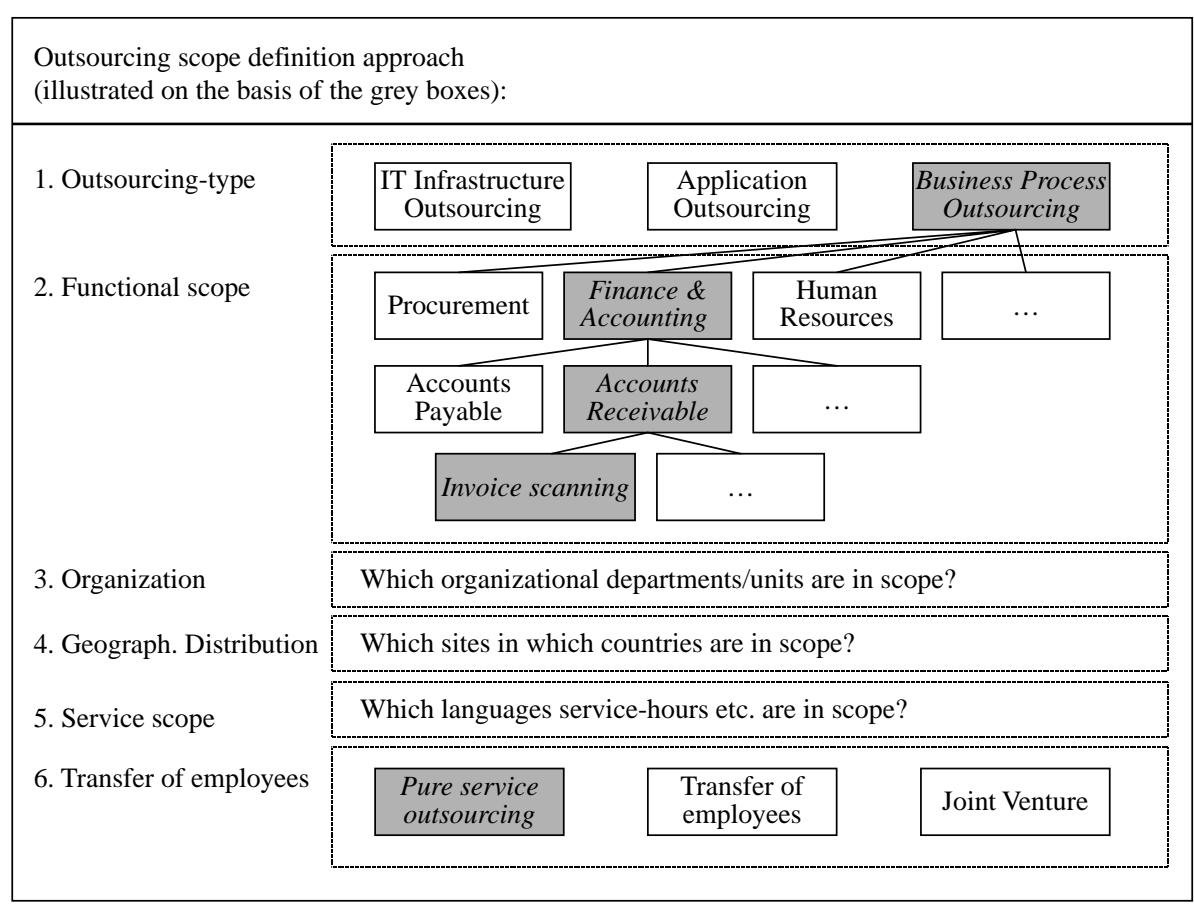

Source: Own

\section{The outsourcing lifecycle}

113

Figure 1. Outsourcing scope definition approach

(type and number of relevant systems), and the corresponding governance model. The baseline also includes current transaction volumes of in-scope services (e.g. number of invoices), as well as as-is cost and cost structure. Also, existing service levels and corresponding measuring parameters, third-party contracts, basic conditions pertaining to legal and fiscal requirements, as well as potential risks and their mitigation have to be clarified. Finally, benchmarks, market prices, and empirical values are needed in order to be able to quantify future savings potentials in relation to the current situation.

The information needs of the assessment phase are rounded off with a definition of the to-be conditions. These include the future operating model and the migration strategy. The operating model covers a description of unit management (location concept, organizational structure, processes, IT support, and risk management), human resources management (personnel structure, requirement profiles, training, and governance concept), and service management (type, scope, and running time of the services to be outsourced, service levels, obligations to cooperate, volumes, prices, and measuring parameter to operationalize the service levels). The migration strategy contains a high-level planning of the transition from the as-is situation to the to-be conditions.

The transition phase should continuously enhance, detail, and validate the information gathered in the assessment phase. Moreover, the exact setup of the to-be delivery organization has to be defined. As already mentioned in the context of 
IMDS

108,1

114

describing the operating model in the assessment phase, the delivery organization includes unit management, human resource management, and service management.

In the context of unit management, the infrastructure (including IT) is set up, organization and processes are implemented, and a risk management is introduced. The human resource management has to ensure a bilateral know-how transfer between company and provider. This can be obtained by contractual relationships with important employees, incentive systems, and a detailed documentation of any task being outsourced. Employees and management must also be recruited and trained according to their future tasks.

Service management is responsible for the entire service reporting. For this, measuring criteria and points need to be defined that drive service reporting. Service reporting is often based on the fundamental balanced scorecard idea, but individually adapted. The reports should be developed hierarchically, so that they can provide different levels of detail depending on the corresponding addressee. Finally, linking the performance of the provider to bonus/penalty regulations should be considered. Apart from the reporting, service management also includes invoicing of the delivered services, managing changing parameters (change request and contract management), and a continuous comparison of current and forecasted performance and costs (business case tracking).

The migration that is conducted after setting up the delivery organization finally requires information concerning project management (including a detailed timetable), the actual transfer and adaptation of in-scope services, change management, and the current project status.

The information needs regarding operations of the to-be conditions in the operations phase are tied to the information needs in the transition phase: unit management requires a continued risk management and human resource management should furthermore ensure a bilateral know-how transfer. Service management now includes the operational execution of the service reporting which should be enhanced with additional performance management activities. These are quality control, customerand user-satisfaction analyses, and root-cause analyses if certain service levels have failed. A continuous improvement process to enhance the outsourced services should be implemented. Further, components of the service management are - as mentioned in the transition phase - invoicing, change request- and contract management, and a continuous business case tracking throughout operations. The full list of information needs is shown in Figure 2.

\section{Round 2: initial evaluation of information needs}

The result of the second questioning round was an evaluation of the information needs raised in round 1 in order to specify their importance to govern and to control the outsourcing provider. The statistical analysis of the returned expert evaluation on a scale from 1 (unimportant) to 5 (very important) included calculating the statistical distribution of frequencies, the mode, and the median. For the additional question (allocation of ranks 1-5), the statistical distribution of frequencies, as well as the sum of all ranks assigned, were again analyzed.

In a first step, the information needs were sorted according to their prioritization by scale in order to identify the most important information needs. For this, the information needs were arranged according to the value of their median, with identical 


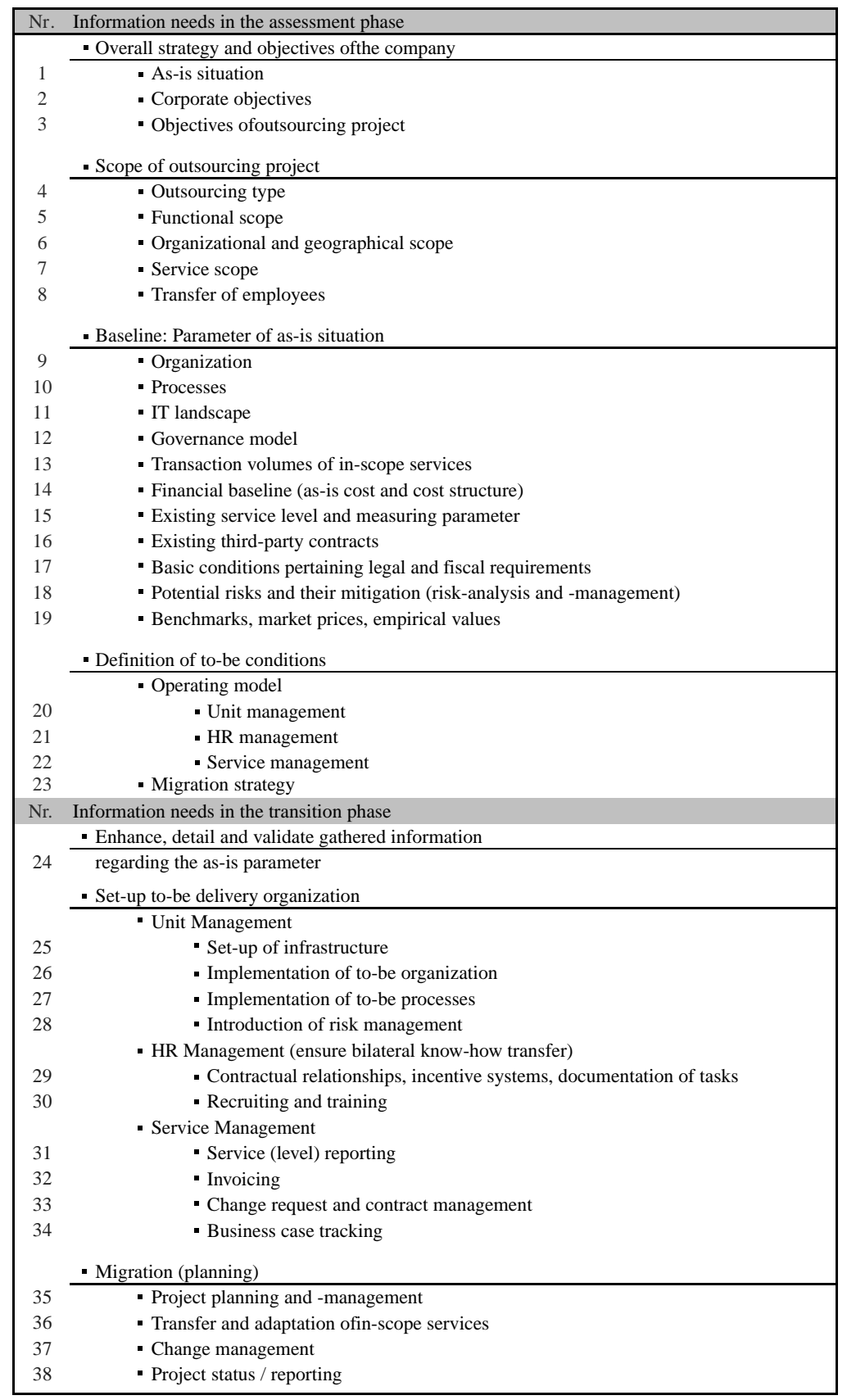

\section{The outsourcing lifecycle}

115
Figure 2.

Full list of consolidated information needs 


\section{IMDS \\ 108,1}

\section{6}

Figure 2.

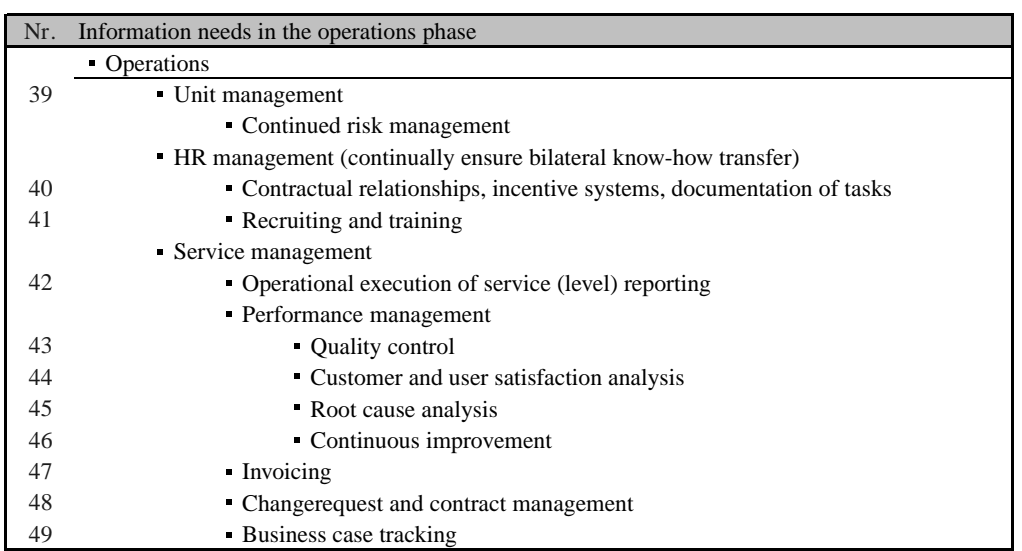

\section{Source: Own}

medians placed together based on the number of received scale values " 5 ," and with a new tie according to their number of received scale values "4." The following order resulted.

The most important information needed to govern and to control the external provider is "quality control" in the operation phase, which includes establishing measures to ensure the quality of the outsourced services (e.g. evaluation of politeness on the part of call center operators). "Quality control" was followed by three identically evaluated information needs: "operational service reporting," "change request- and contract-management" in the operation phase, and "business case tracking" in the transition phase.

"Operational service reporting" covers the operations of a performance measurement system and of corresponding reports as a major information source about the performance of delivered services. "Change request- and contract management" includes the management of changing parameters (e.g. new requirements or changing volumes) during the operations phase, and "business case tracking" compares current and (in the transition phase) forecasted performance and costs. Fifth place was taken by the "objectives of the outsourcing engagement" that are discussed in the assessment phase. A detailed evaluation of the top five information needs is shown in Figure 3.

In order to validate and assure the results of the prioritization by scale, a second evaluation step was conducted. The most important information needs were prioritized according to the allocation of ranks resulting from the additional question. Here, information needs were sorted first of all according to the sum of all ranks assigned to each information need, with identical sums according to the number of received ranks " 1 ," and with a new tie coming from the number of received ranks " 2 ." The following order resulted.

The most important information need is "operational service reporting," followed at a distance by the information needs "service reporting" in the transition phase, which covers the definition and implementation of a performance measurement system and of corresponding reports, and "change request- and contract management" in the operations phase. Position 4 and 5 were captured by the "objectives of the 
Distribution of frequencies of top 5 information needs (according to scale assessment):
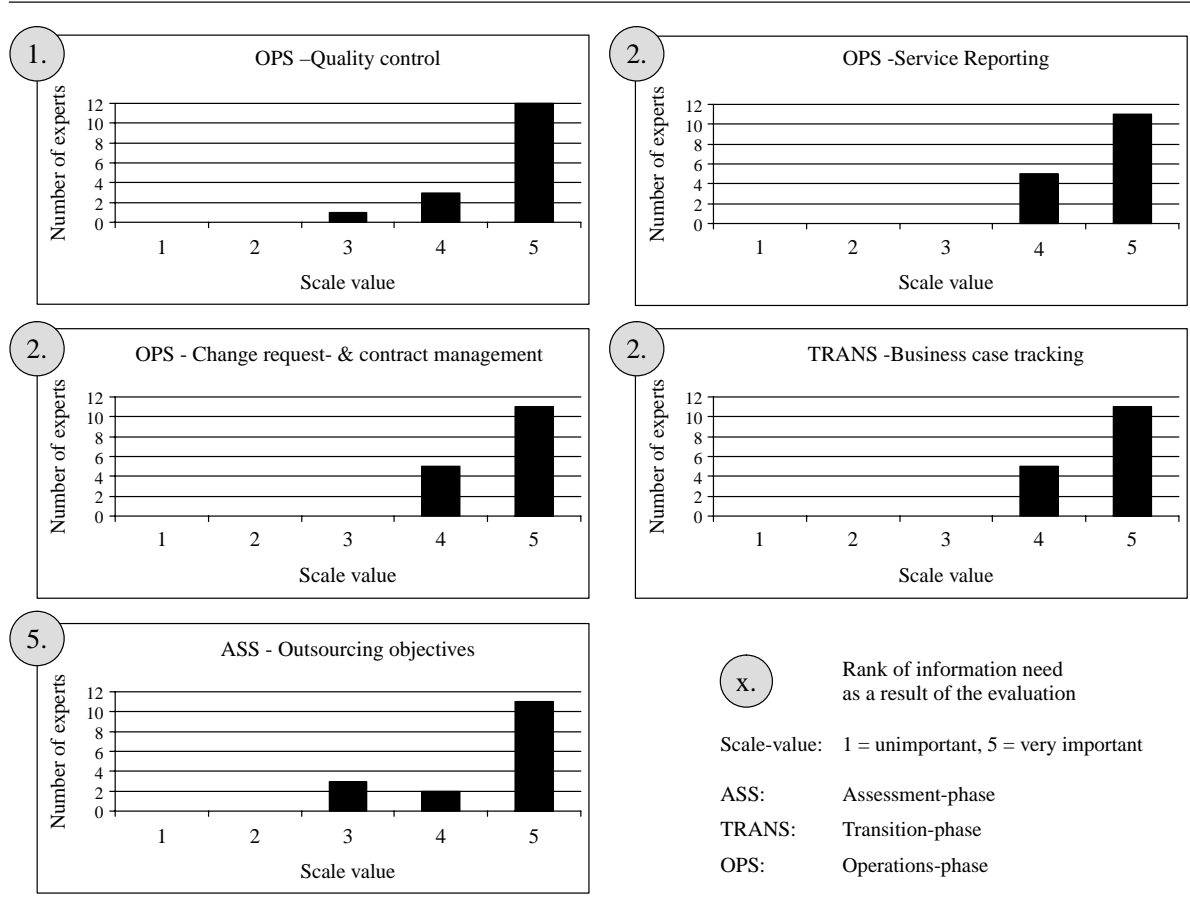

Source: Own

outsourcing-engagement" that are discussed in the assessment phase and by "quality control" in the operations phase. A detailed evaluation of the top five information needs is shown in Figure 4.

\section{Round 3: adjustment of initial evaluation}

Round 3 aimed to re-evaluate the results of round 2 based on a comparison of the individual evaluation of each expert with the statistically evaluated group opinion, and to adapt the individual evaluation if necessary. Owing to the illustrative results from round 2, however, none of the experts saw further adjustment needs. Thus, a stop criterion of the study was already (and unwillingly) reached: the results of the preceding round could not be further improved via the following questioning round (Schmidt, 1997). The results of the second questioning round therefore also represent the final results of the Delphi study.

\section{Overall, assessment of results}

A comparison of both statistical evaluations shows that the prioritization of the most important information needs made by the experts were based on:

- the scale assessment; and

- the assignment of ranks are nearly congruent.

\section{The outsourcing lifecycle}

Figure 3.

Distribution of frequencies of the top five information needs (according to scale assessment) 
IMDS

108,1

\section{8}

Figure 4.

Distribution of frequencies of top five information needs (according to distribution of ranks)
Distribution of frequencies of top 5 information needs (according to distribution of ranks):
Rank allocation

[Number of nominations]

\begin{tabular}{|c|c|c|c|c|c|c|c|}
\hline Rank & Information needs & Phase & 5 . & 4. & 3. & 2. & 1. \\
\hline & Service Reporting & Operations & & 1 & 1 & 2 & 4 \\
\hline & Service Reporting & Transition & & & 2 & 2 & 2 \\
\hline & $\begin{array}{l}\text { Change request-and } \\
\text { contract-management }\end{array}$ & Operations & 2 & 2 & 1 & 1 & \\
\hline & Outsourcing objectives & Assessment & 1 & 1 & 1 & 1 & 1 \\
\hline & Quality control & Operations & 2 & 1 & 1 & 1 & \\
\hline
\end{tabular}

(x.) Rank of information need as a result of the evaluation

\section{Source: Own}

The results are therefore confirmed and methodically secured by the additional question.

The results from both questions contain four equal information needs within the top five items. The topic of "service reporting" is particularly notable. It achieved a first place rank and a second place (scale) in the context of the operations phase and was thus evaluated in sum as the most important information need for governing and controlling the external provider. This placement is underlined by a second place (rank) of "service reporting" in the transition phase. Since, the reporting is developed and implemented in the transition phase, and then carried out in the operations phase, these two information needs are directly connected with each other.

In addition, "change request- and contract-management" in the operations phase (second and a third place), "quality control" in the operation phase (first and fifth place), and the "objectives of the outsourcing engagement" from the assessment phase (fourth and a fifth) place have to be mentioned, which were also ranked twice among the top five information needs.

\section{Discussion}

While there is a rapidly growing body of literature on outsourcing, there is hardly any account reporting which information needs have to be fulfilled in outsourcing projects along their lifecycle. This is the major contribution of the present paper. Based on a Delphi study with outsourcing experts, related information needs were identified and prioritized. One major limitation of the approach lies in selecting the experts solely from inside one of the leading global outsourcing companies. This might have biased 
the results, but as described in the research methodology section, different measures were put in place to take this into account. The strength of the approach is that a first set of issues can be identified in such an exploratory approach. It is planned to conduct several case studies as a next step in the research. This should allow a comparison of the outsourcing information needs to those identified in this study regarding specific cases.

Processes for structuring the outsourcing and make-or-buy decision have been presented in numerous papers (de Boer et al., 2006; Momme and Hvolby, 2002; McIvor, 2000) and related performance indicator sets have been developed. This paper points out which particular information needs have to be fulfilled for managing any outsourcing project. This should help researchers to further discuss the role of management accounting tools and how they are to be used to justify and support outsourcing decisions and the ongoing management of outsourced processes. Further, practitioners can take this as a starting point to improve the information basis for their own outsourcing decisions.

\section{Conclusion}

The Delphi study considered the opinion of 16 outsourcing experts in a three-round survey in order to develop information needs in the outsourcing lifecycle and to prioritize them according to their importance for governing and controlling the outsourcing provider. The study aimed to shed light on this infrequently-considered research field. It provides a documentation of information needs as a first result for affected companies, and creates a basis for further research activities.

The evaluation of information needs resulted in a ranking of "service reporting" as the number one information need. Service reporting usually comprises the implementation and operations of performance measurement systems and their respective reports to give information about the performance of outsourced services. Affected companies should therefore pay particular attention to the implementation of an effective "service reporting" in order to realize a successful outsourcing, and particularly to ensure that the provider is delivering the contracted performance. Future scientific research activities should explicitly examine how to effectively design "service reporting" in theory and practice.

\section{References}

Atkinson, A.A., Kaplan, R.S. and Young, S.M. (2003), Management Accounting, Prentice-Hall, Upper Saddle River, NJ.

Aubert, B.A., Rivard, S. and Patry, M. (2004), "A transaction cost model of IT outsourcing", Information \& Management, Vol. 41, pp. 921-32.

Bragg, S.M. (1998), Outsourcing, Wiley, Hoboken, NJ.

Brown, D. and Wilson, S. (2005), The Black Book of Outsourcing, Wiley, Hoboken, NJ.

Cheon, M.J., Grover, V. and Teng, J.T.C. (1995), "Theoretical perspectives on the outsourcing of information systems", Journal of Information Technology, Vol. 10, pp. 209-19.

Click, R.L. and Duening, T.N. (2005), Business Process Outsourcing, The Competitive Advantage, Wiley, Hoboken, NJ.

Dalkey, N. and Helmer, O. (1963), "An experimental application of the Delphi method to the use of experts”, Management Science, Vol. 9 No. 3, pp. 458-67.

\section{The outsourcing lifecycle}

119 
IMDS

108,1

120 de Boer, L., Gaytan, J. and Arroyo, P. (2006), "A satisfying model of outsourcing”, Supply Chain Management - An International Journal, Vol. 11 No. 5, pp. 444-55.

Dibbern, J., Goles, T., Hirschheim, R. and Jayatilaka, B. (2004), "Information systems outsourcing: a survey and analysis of the literature", The DATA BASE for Advances in Information Systems, Vol. 35 No. 4.

Drury, C. (2004), Management and Cost Accounting, Thomson, London.

Ezzamel, M., Morris, J., Smith, J.A. and White, A. (2002), "Accounting for new organisational forms: initial findings on sub-contracting and outsourcing in the UK", Management Research News, Vol. 28, pp. 54-7.

Friedman, T.L. (2006), The World is Flat: A Brief History of the Twenty-first Century, Audio Renaissance, New York, NY.

Grover, V., Cheon, M.J. and Teng, J.T.C. (1994), "A descriptive study on the outsourcing of information systems functions", Information \& Management, Vol. 27 No. 1, pp. 33-44.

Häder, M. (2002), Delphi-Befragungen, Westdeutscher Verlag, Wiesbaden.

Harland, C., Knight, L., Lamming, R. and Walker, H. (2005), "Outsourcing: assessing the risks and benefits for organizations, sectors and nations", International Journal of Operations \& Production Management, Vol. 25 No. 9, pp. 831-50.

Holcomb, T.R. and Hitt, M.A. (2007), "Toward a model of strategic outsourcing", Journal of Operations Management, Vol. 25 No. 2, pp. 464-81.

Johnson, R.E., Johnson, T. and Arab, R.A. (2006), "Coping with outsourcing: an interaction and network perspective", Problems and Perspectives in Management, Vol. 4 No. 2, pp. 78-85.

Juma'h, A.H. and Woods, D. (1999), "Outsourcing implications for accounting practices", Managerial Auditing Journal, Vol. 14 No. 8, pp. 387-95.

Kakabadse, A. and Kakabadse, N. (2005), "Outsourcing: current and future trends”, Thunderbird International Business Review, Vol. 47 No. 2, pp. 183-204.

Kakabadse, N. and Kakabadse, A. (2000), "Outsourcing: a paradigm shift", Journal of Management Development, Vol. 19 No. 8, pp. 670-728.

Ketler, K. and Walstrom, J. (1993), "The outsourcing decision", International Journal of Information Management, Vol. 13, pp. 449-59.

Linstone, H.A. and Turoff, M. (Eds) (2002), The Delphi Method: Techniques and Applications, Addison-Wesley, Reading, MA, Online edition of the original published, 1975.

Lünendonk, T. (2006), Der Markt für Business Innovation/Transformation Partner (BITP) in Deutschland, Lünendonk, Bad Wörishofen.

McIvor, R. (2000), “A practical framework for understanding the outsourcing process", Supply Chain Management: An International Journal, Vol. 5 No. 1, pp. 22-36.

May, A.S. (1998), "Business process outsourcing: a new test of management competence", Career Development International, Vol. 3 No. 4, pp. 136-41.

Momme, J. and Hvolby, H-H. (2002), "An outsourcing framework: action research in the heavy industry sector", European Journal of Purchasing \& Supply Management, Vol. 8 No. 4, pp. 185-96.

Neuendorf, K.A. (2002), The Content Analysis Guidebook, Sage, Thousand Oaks, CA.

Okoli, C. and Pawlowski, S.D. (2004), "The Delphi method as a research tool: an example, design considerations and applications", Information \& Management, Vol. 42, pp. 15-29.

O'Reilly, C.A. (1983), "The use of information in organizational decision making: a model and some propositions", Research in Organizational Behavior, Vol. 5, pp. 103-39. 
Peisch, R. (1995), "When outsourcing goes awry", Harvard Business Review, Vol. 73 No. 3, pp. 24-30.

Poppo, L. and Zenger, T. (1998), "Testing alternative theories of the firm: transaction cost, knowledge-based, and measurement explanations for make-or-buy decision in information services”, Strategic Management Journal, Vol. 19, pp. 853-77.

Power, M.J., Desouza, K. and Bonifazi, C. (2006), The Outsourcing Handbook, Kogan Page, London.

Quinn, J.B. and Hilmer, F.G. (1994), "Strategic outsourcing”, Sloan Management Review, Summer, pp. 43-55.

Ravi, R., McStravick, P., Bingham, B., Rowan, L. and Loynd, L. (2006), "Worldwide and US business process outsourcing 2006-2010 forecast: market opportunities by horizontal business process", available at: www.idc.com

Schmidt, R.C. (1997), "Managing Delphi surveys using nonparametric statistical techniques", Decision Sciences, Vol. 28 No. 3, pp. 763-74.

Sciulli, N. (2004), "The use of management accounting information to support contracting out decision making in the public sector", Qualitative Research in Accounting \& Management, Vol. 1 No. 2, pp. 43-67.

Smith, J.A., Morris, J. and Ezzamel, M. (2005), "Organisational change, outsourcing and the impact on management accounting", The British Accounting Review, Vol. 37 No. 4, pp. $415-41$.

\section{Corresponding author}

Stefan Seuring can be contacted at: seuring@uni-kassel.de

To purchase reprints of this article please e-mail: reprints@emeraldinsight.com Or visit our web site for further details: www.emeraldinsight.com/reprints 